\title{
HEMATOMAS IN THE HEART VALVES OF CALVES *
}

\author{
LAURA FLORENCE, PH.D. \\ PRINCETON, N. J.
}

The presence of hematomas in the heart valves of new-born calves is today a widely known fact. Nevertheless, a survey of veterinary literature reveals only brief references, and, since in these the microscopic structure and possible origin of the hematomas have not been discussed, a study of these two points was undertaken. The literature describing hematomas in the heart valves of children was not consulted until the conclusion of the work on calves.

Kitt ${ }^{1}$ describes the hematomas as being bladders of blood or serous fluid, varying in size from a lentil to a pea, situated between the flat endocardial folds of the artioventricular valves, and raised somewhat above the surface of the valve. He gives no references but cites Glage and Kläger, whose observations agree with his own on slaughtered swine and young calves, and Gibson who had seen similar small cysts in lambs. Ostertag ${ }^{2}$ refers to the hematomas as true hemorrhages, which he considers normal and not infrequent in young calves. He also cites Kläger. In 1914 Egge $^{3}$ published a short paper and in the same year another reference appeared in the textbook of Jost and Koch. ${ }^{4}$ The latter add nothing to the description of Kitt. From 1905 to the time of publication, Egge examined the hearts of young calves slaughtered in the abattoirs under his care, and in the heart valves of almost all the animals he found extravasations consisting, in part, of sharply defined swollen blood tumors varying in size from a pinpoint to a pea, and in part of more or less large level areas of blood in the tissue of the valvie. These were situated in the region of attachment of the chordae tendinae. He also examined the hearts of fetuses and prematurely born calves with positive results. He did not find hemorrhages in calves that had lived four or five weeks, and concluded that the blood must be absorbed during the first weeks of extra-uterine life. He offers no explanation of the presence of these hemorrhages and refers only to the work of Ostertag. He also examined the hearts of foals, young swine, and lambs, but never found any extravasations.

* Received for publication, Oct. 17, 1921.

* From the Department of Animal Pathology of The Rockefeller Institute for Medical Research.

1. Kitt, T.: Pathologische Anatomie der Haustiere 2:310, 1906; Ibid. 2: $337,1911$.

2. Ostertag, R. von: Handb. d. Fleischbeschau, Stuttgart 1:263, 1910.

3. Egge, G.: Berl. Tierärtzl. Wchnschr. 4:63, 1914.

4. Jost, J., and Koch, M.: Krankheiten junger Tiere im Vergleich mit Kinderkrankheiten, 1914, p. 631. 
We have been unable to find the original references of Glage, Kläger and Gibson.

Similar hematomas are of frequent occurrence in the heart valves of new-born and young children, and they have been seen in the human fetus and in still-born children. The literature has been carefully reviewed by Wegelin, ${ }^{5}$ consequently only a brief summary is given here. Luschka, ${ }^{6}$ who cited Elsässer ${ }^{7}$ as the first to mention hematomas in the heart valves, accurately described their macroscopic appearance and attributed their origin to hemorrhage, due to ruptured vessels, into the soft tissue of the noduli albini. Parrot ${ }^{8}$ also thought that they were formed through the rupture of intravalvular blood vessels after birth but regarded the noduli albini as resulting from the organization of this hemorrhage. In 1898 Berti $^{9}$ published an entirely new view. $\mathrm{He}$ discovered the endothelium lining the blood cavities and concluded that they were not hematomas but varicose vessels or blood cysts due to changes in the pre-existing blood vessels. He also examined a number of animal hearts and pictured a cyst in the atrioventricular valve of a four-weeks-old lamb. The same year Haushalter and Thiry ${ }^{10}$ described a connective tissue layer and not endothelium surrounding the blood cavities and again named them hematomas. They saw no vessels in the valves in the neighborhood of the hematomas, but in serial sections traced a connection between them and the cavity of the ventricle. They thought the blood was forced into the bays on the under surface of the valve at birth and in earliest infancy, and that the soft tissue gave way before the pressure allowing the blood to penetrate the valve. This blood was then dammed back in the tissue during the ventricular systole through the stretching of the valve and the pull of the chordae tendinae. This view was severely criticized by Berti. ${ }^{11}$ Fahr ${ }^{12}$ examined the hearts of children during the first months of life and in almost every case found hematomas in the valves. He also found them in most of the fetuses he examined from the sixth month of development. Like Berti ${ }^{9}$ he saw the endothelium lining the blood cavities and thought them vessel ectases. Wegelin ${ }^{5}$ described the histologic structure in great detail and figured serial sections to demonstrate his theory of the formation of the hematomas. He agreed with Haushalter and Thiry that they were formed by the

5. Wegelin, C.: Frankfurter Ztschr. f. Path. 2:411, 1909.

6. Luschka, H.: Virchows Arch. f. path. Anat. 11:144, 1857.

7. Elsässer: Bericht über die Ereignisse in der Gebäranstalt des Catharinenhospitals, Stuttgart, 1844.

8. Parrot, J.: Arch. de physiol. norm. et path. 1:538, 1874.

9. Berti, G.: Boll. delle sc. med. di Bologna, 1898, pp. $343,479,581$; Referat, München. med. Wchnschr., 1898.

10. Haushalter, P., et Thiry, Ch.: Arch. de méd. expér. 10:558, 1898.

11. Berti, G.: Arch. f. Kinderh. 31:371, 1901.

12. Fahr: Virchows Arch. f. path. Anat. 184:274, 1906. 
forcing of the blood against the valves, but he also recognized the endothelial lining of the cavities and said they arose through the widening and secondary cutting off of some of the bays which lie normally on the ventricular side of the valve where the chordae tendinae are attached. Just after Wegelin had finished his investigation, but before the publication of his results, two further papers appeared. Meinhardt ${ }^{13}$ had arrived independently at practically the same conclusions as Wegelin. Hammes ${ }^{14}$ also saw the narrow canals connecting the blood cavities with the ventricle, but agreed with Berti in considering the hematomas ectases of true vessels. Also he thought they had no connection with the coronary system but constituted a second type of valve vessel serving to nourish the valves during the last third of fetal life and the first year of extra-uterine life.

During the past five years accumulations of blood have been seen very frequently in the tissues of the atrioventricular valves in the fetuses and young calves examined in this institute. These have not been found in the semilunar valves of calves by us or by Egge, but they have been recorded by a number of pathologists as occurring in these valves in children. As stated by Egge, these accumulations of blood are of two distinct types. There are clearly defined hematomas varying in size from a pinpoint to a large pea; the largest one sectioned had a diameter of $6 \mathrm{~mm}$. They are usually subcircular, but frequently a few very small hematomas are scattered close around the border of the larger ones giving a false appearance of an irregular edge. There may be one or several in a valve, and occasionally we have seen a number of small ones clustered together, resembling somewhat the surface of a blackberry and extending over the greater part of the valve. They are slightly raised above the atrial surface but not so much so as those in children as described by Berti and Wegelin, and are visible from both surfaces of the valve. They are usually blackishred in color, but sometimes they are bright red. Most are firm to the touch and evidently quite filled with blood, but occasionally some are not fully distended and are soft to the touch, so that their form changes somewhat under pressure. The second type is hemorrhage over a level area of irregular outline and not at all elevated above the surrounding surface; some of these have been found bright red and others blackish-red in the fresh state. In one case of a calf, which died when two days old, hemorrhage extended around the entire set of valves of the right side of the heart, while numerous hematomas were present in the valves of the left side. Both types are situated among the attachments of the chordae tendinae.

13. Meinhardt, H.: Virchows Arch. f. path. Anat. 192:521, 1908.

14. Hammes, F.: Virchows Arch. f. path. Anat. 193:238, 1908. 
Valves from the hearts of eight calves, varying in age from one day to three months, have been studied microscopically by means of serial sections stained with eosin and methylene blue, hematoxylin and eosin, and by the Gram-Weigert method. The two types of hemorrhage present very distinct pictures. In the case of the hematomas our findings are similar to those of Wegelin, although our interpretation of them is somewhat different. In every case there was a clearly defined cavity lined with a single layer of endothelium and well filled with blood cells among which the mononuclear and polynuclear elements were present in normal numbers. In a few cases in which the cavity was much distended there was crowding of the surrounding tissue which gave a false appearance of a connective tissue capsule. The largest hematomas extended into the region of the muscle at the attached border of the valve. In no case were true blood vessels found communicating with the hematomas, but their connection with surrounding slender endothelial-lined channels and clefts could frequently be traced through successive sections, while at other times chains of endothelial cells with large dark-staining nuclei and a narrow border of cytoplasm were the only trace of original channels. Neighboring hematomas were often seen to become confluent with one another and form large blood-filled cavities which in later sections again divided into small cavities. In children Haushalter and Thiry described the disappearance of the hematomas through destruction of the red cells, accumulations of fibrin, invasion of the blood by round cells, and by budding. Wegelin also saw the hematomas obliterated through the changing of the red cells into a hyalin mass and its subsequent organization by the outgrowth of endothelial and connective tissue cells. In the oldest calves studied, traces of budding of endothelial and connective tissue cells were seen in the hematomas, but never such accumulations of fibrin as Haushalter and Thiry described or the collections of pigment mentioned by them and by Wegelin. These accumulations of blood are either organized or absorbed, since they are not found in older animals.

A study of serial sections of the level areas of blood showed that they were due to an extravasation of blood into the tissue of the valve. Where much blood had escaped the structure of the valve was entirely - concealed but in other cases numerous capillaries and clefts were seen. In none of the sections was there any evidence of rupture and the blood had apparently escaped from the vessels by diapedesis. Such a condition, while tolerably frequent in calves, is evidently unusual in children, since Wegelin alone mentioned small hemorrhages under the endothelium and in the tissue surrounding small hematomas. In none of the cases studied have any other pathologic conditions been found in the valves. 
In the majority of the calves having blood accumulations in the heart valves punctiform hemorrhages are frequently seen in the alimentary tract, particularly in the fourth stomach and in the pyloric and ileocecal valves and rectum. Their importance, owing to their opening a way of infection, and their possible connection with the hematomas and hemorrhages of the heart valves will be discussed in a later paper.

\section{DISCUSSION}

Three different views have been stated concerning the source of the hematomas found in the heart valves of children: first, that they were the result of hemorrhage; second, that they were ectases of true blood vessels; and third, that they were the result of the forcing of blood into the soft tissues of the valve during the ventricular systole. Each view has with various modifications been supported by a number of investigators and both Berti and Wegelin have discussed the question at considerable length. The present study has suggested another origin.

Since hematomas are found only in the valves of fetuses and very young animals their-origin must be looked for in the course of the development of the heart. Minot ${ }^{15}$ first pointed out that in all vertebrates there occur two types of blood vessels with endothelial walls only, namely, capillaries and a second form which he named sinusoids. The facts of the development of the cardiac trabeculae were already well known, but Minot first interpreted the condition as a sinusoidal circulation and as showing the primitive circulation of the heart itself. Only later when the coronary arteries develop is a true capillary circulation formed. His study of embryos led him to conclude that for a time the nourishment of the heart is direct, from its own contained blood. Lewis ${ }^{16}$ confirmed Minot's work and showed both in fish and rabbits that the heart has a superficial capillary and a deep sinusoidal circulation wholly different in their development. In adult fishes and amphibians the sinusoids remain highly developed while in mammals they undergo a regression. According to Lewis many sinusoids are "reduced to strands of endothelium without lumen. Others are retained as slender vessels opening into the ventricle at both ends. These are probably the source of those vessels of Thebesius described by Langer ${ }^{*}$.in adult human hearts, as associated with the papillary muscles and communicating at both ends with the ventricle. Other sinusoids remain large, and seem to anastomose with the coronary vessels suggesting the free communication between the ventricles and coronary veins found by Pratt ${ }^{18}$ in the heart of calves."

15. Minot, C. S.: Proc. Boston Soc. Nat. Hist. 29:185, 1900.

16. Lewis, F. I.: Anat. Anz. 25:261, 1904.

17. Langer, L.: Sitz.-Ber. d. Akad. d. Wiss. Wien. 82:25, 1881. Quoted by Lewis. ${ }^{16}$

18. Pratt, F. H.: Am. J. Physiol. 1:86, 1898. Quoted by Lewis. ${ }^{18}$ 
In the course of their development the anlagen of the valves are connected with the trabeculae of the ventricles. The muscle bundles on the atrial surface of the valve anlagen pass toward the ventricles and are apparently continuous with the ventricular bundles so that for a time the valve cusps consist partly of endocardial growths and partly of musculature. At first the endocardial growths greatly surpass the muscular and later the trabeculae which pass from the spongy substance of the ventricles to the valves increase greatly and the central portions of the valves come to project further into the lumen. The trabeculae separate from the corticalis and pass more toward the center and at the same time the musculature of the valves undergoes considerable development. Later this musculature of the valve is replaced by connective tissue and elastic threads and the trabeculae become transformed into chordae.

During the period of intimate connection between the trabeculae and developing valves the sinusoidal circulation doubtless penetrates and nourishes the latter. It seems reasonable then to infer that the hematomas are vestiges of the primary sinusoidal circulation of the heart, and that the strings of cells, slender vessels, and smaller clefts seen in all sections of valves are also vestiges of sinusoids and, as Lewis suggests, may be the vessels of Thebesius. Among previous workers only Hammes suggested that the hematomas and small vessels might be a distinct circulation apart from the coronary circulation.

In studying serial sections of the true hemorrhages, capillaries and small clefts congested with blood were seen wherever the hemorrhage was not so abundant as to conceal all the structure of the tissue. In successive sections these vessels could not be traced to any connection with larger vessels toward the base of the valve, so it must be inferred that they are some of the vessels of Thebesius and that the hemorrhage has taken place by diapedesis through their walls.

The existence of such an independent innner circulation in the heart may also account for the great variety of opinion as to whether the atrioventricular valves are vascular or not. The most recent work we have seen is that of Argaud. ${ }^{19}$ He concluded that in oxen, as in man, blood vessels are sometimes present in the valves, and that in horses they are always present.

Hematomas have not been recorded as occurring in the semilunar valves in animals, and in children much less frequently in these than in the atrioventricular valves. Wegelin considered this to be the result of the small number of invaginations on the surface of the valve and the small quantity of elastic threads in the tissue, while in accordance with our hypothesis it would be due to the great restriction of trabeculae in the atria. In spite of the fact that the small quantities of blood

19. Argaud, R.: Compt rend. Soc. biol. 62:812, 1912. 
invariably present in the bays between the chordae tendinae and communicating with the cavity of the ventricle suggest the formation of the hematomata by the forcing of the blood into deeper bays as Wegelin and Meinhardt have concluded, their interpretation as remains of the primary sinusoidal circulation seems a more natural process.

These cavities filled with blood are not true hematomas, and some writers have suggested that they be called blood cysts. Only a microscopic study of the valves of fetuses at different stages of development will actually prove our hypothesis of their origin as sinusoids and till then we propose to retain the name hematoma.

\section{CONCLUSIONS}

Hematomas and hemorrhages are of frequent occurrence in the atrioventricular valves of fetuses and young calves. Both are situated in the region of attachment of the chordae tendinae and may occur in the same valve.

The hematomas are subcircular cavities lined with a single layer of endothelial cells and may be sinusoids which persist from the primary sinusoidal circulation of the heart.

The hemorrhages apparently occur by diapedesis from the vessels of Thebesius.

No other pathologic conditions have been found in the affected valves. 